\title{
ASHIMYCINS A AND B, NEW STREPTOMYCIN ANALOGUES
}

\author{
Susumu Tohma, Haruo Kondo, Junko Yokotsuka, Junj Iwamoto, \\ Gen Matsuhashi and Tatsuo Ito \\ Pharmaceutical Technology Laboratories, Meiji Seika Kaisha, L.td., \\ Kayama, Odawara-shi, Kanagawa 250-01, Japan \\ Haruo Seto \\ Institute of Applied Microbiology, The University of Tokyo, \\ Yayoi, Bunkyo-ku, Tokyo 113, Japan \\ (Received for publication April 17, 1989)
}

\begin{abstract}
Detailed analysis of the fermentation broth of Streptomyces griseus strain FT3-4 resulted in the identification of two new streptomycin analogues named ashimycins A and B. Their structures have been determined by NMR spectral analysis and chemical degradations.
\end{abstract}

During the attempts to improve the fermentation yield of streptomycin by Streptomyces griseus strain FT3-4, we noticed that the lower production yield of streptomycin was sometimes accompanied by the accumulation of new metabolites structurally related to streptomycin. We will report herein the fermentation, isolation, physico-chemical properties, structural elucidation and biological activities of these compounds named ashimycins A and B.

\section{Fermentation}

Ashimycins A and B have been isolated from the culture filtrate of Streptomyces griseus strain FT3-4 which is being used for commercial production of streptomycin at our company. A well-grown agar slant of the strain FT3-4 was used to inoculate $20 \mathrm{ml}$ of a seed culture medium consisting of corn steep liquor $3.0 \%$, yeast $0.25 \%$ and $\mathrm{CaCl}_{2} \cdot 2 \mathrm{H}_{2} \mathrm{O} 0.1 \%(\mathrm{pH} 7.5$ ) in a $100-\mathrm{ml}$ Erlenmeyer flask. The flask was shaken on a rotary shaker $(220 \mathrm{rpm})$ at $28^{\circ} \mathrm{C}$ for 27 hours, and then $4 \mathrm{ml}$ of the culture was transferred to $80 \mathrm{ml}$ of the same medium in a $500-\mathrm{ml}$ Erlenmeyer flask. After shaking at $28^{\circ} \mathrm{C}$ for 21 hours, $80 \mathrm{ml}$ of the broth was used to inoculate $1,000 \mathrm{ml}$ of the same medium in a 5-liter Erlenmeyer flask, and the fermentation was continued at $28^{\circ} \mathrm{C}$ for 30 hours. This seed culture was added to a 30 -liter jar fermenter containing 20 liters of a production medium composed of soybean meal $5.0 \%$, glucose $5.0 \%$, mannose $0.5 \%$ and $\mathrm{KH}_{2} \mathrm{PO}_{4} 0.1 \%$, pH being adjusted to 7.6 before sterilization. The final fermentation was carried out at $28^{\circ} \mathrm{C}$ for 6 days with an agitation rate of $250 \mathrm{rpm}$ and aeration of 8 liters per minute.

\section{Isolation and Purification}

The procedures for isolating a crude streptomycin complex and purifying the individual components are schematically shown in Fig. 1. Active substances were traced by the maltol reaction after separation by analytical HPLC (column: CK10S, Mitsubishi Chemical Industries Limited, 7.0 250 $\mathrm{mm}$; solvent: linear gradient from 0.2 to $1.0 \mathrm{M} \mathrm{Na}_{2} \mathrm{SO}_{4}$, flow rate: $1.0 \mathrm{ml} /$ minute). The broth filtrate contained the ashimycins in addition to mannosidostreptomycin and streptomycin as shown in Fig. 2.

The broth filtrate was adsorbed on an Amberlite IRC-50 column ( $\mathrm{Na}^{+}, 4.8$ liters), and elution with 
Fig. 1. Isolation scheme for ashimycins $\mathbf{A}$ and $\mathbf{B}$.

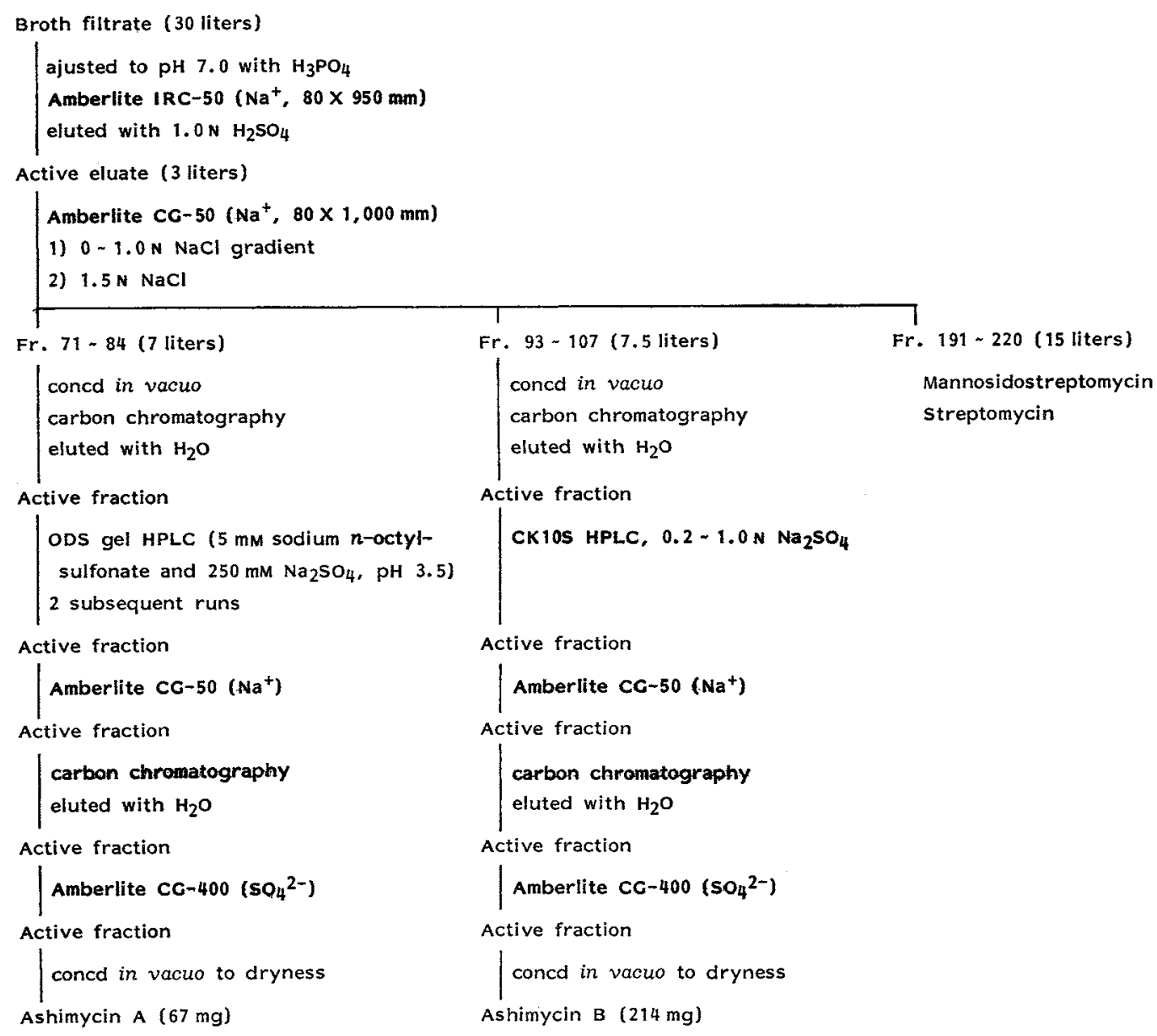

$1.0 \mathrm{~N} \mathrm{H}_{2} \mathrm{SO}_{4}$ gave an active eluate (3 liters) which was concentrated to give a crude powder (269 $\mathrm{g}$ ). Separation of the individual antibiotics was achieved by Amberlite CG-50 column chromatography $\left(\mathrm{Na}^{+}, 80 \times 1,000 \mathrm{~mm}\right)$ developed with a $0 \sim 1.0 \mathrm{~N} \mathrm{NaCl}$ gradient (72 liters). The eluate was cut into 0.5-liter fractions. Ashimycin A was eluted in fractions $71 \sim 84$ and ashimycin B in fractions $93 \sim 107$. Mannosidostreptomycin and streptomycin were eluted by $1.5 \mathrm{~N} \mathrm{NaCl}$.

Ashimycin A was further purified by carbon column chromatography (Wako, activated carbon, $40 \times 360 \mathrm{~mm}$ ) eluted with water followed by liquid chromatography on YMC-ODS (Shimakyu, Co. $50 \times 500 \mathrm{~mm}$, equilibrated with an aqueous solution containing $5 \mathrm{~mm}$ of sodium $n$-octylsulfonate and $250 \mathrm{~mm}$ of sodium sulfate adjusted to $\mathrm{pH} \mathrm{3.5)} \mathrm{developed} \mathrm{with} \mathrm{the} \mathrm{same} \mathrm{solution.} \mathrm{The} \mathrm{purification}$ procedure by liquid chromatography was repeated twice. The concentrated fraction containing ashimycin $\mathrm{A}$ was adsorbed on a column of Amberlite CG-50 $\left(\mathrm{Na}^{+}, 60 \times 360 \mathrm{~mm}\right)$ followed by elution with a gradient from $0 \sim 1.0 \mathrm{~N} \mathrm{NaCl}$. The active fraction was concentrated and was subjected to carbon column chromatography $(10 \times 64 \mathrm{~mm})$ developed with water. The concentrated active solution of the eluate was adsorbed on a column of Ambrelite CG-400 ( $\left.\mathrm{SO}_{4}{ }^{2-}, 12 \times 88 \mathrm{~mm}\right)$ and developed with water to yield a colorless hygroscopic powder of ashimycin A sulfate $(67 \mathrm{mg})$. 
Ashimycin B was purified by carbon chromatography $(40 \times 360 \mathrm{~mm})$ eluted with water followed by liquid chromatography on CK10S $(10 \mu \mathrm{m}, 50 \times 500 \mathrm{~mm})$ with a $0.2 \sim 1.0 \times \mathrm{Na}_{2} \mathrm{SO}_{4}$ gradient system. The concentrated solution was adsorbed on a column of Amberlite CG-50 ( $\left.\mathrm{Na}^{+}, 60 \times 360 \mathrm{~mm}\right)$ and eluted with a gradient from $0 \sim 1.0 \mathrm{~N} \mathrm{NaCl}$. The active fraction was concentrated and was subjected to carbon column chromatography $(10 \times 64 \mathrm{~mm})$ developed with water. The concentrated active solution of the eluate was adsorbed on a column of Amberlite CG-400 ( $\left.\mathrm{SO}_{4}{ }^{2-}, 12 \times 88 \mathrm{~mm}\right)$ and developed with water to yield a colorless powder of ashimycin B sulfate $(214 \mathrm{mg})$.

\section{Physico-chemical Properties}

Physico-chemical properties of ashimycins A and $\mathrm{B}$ are listed in Table 1. Both compounds were soluble in water and insoluble in methanol and chloroform. The molecular formula of ashimycins $\mathrm{A}$ and $\mathrm{B}$ were determined by secondary ion mass spectrometry (SI-MS) and elemental analysis. The IR absorption at 1660 1630 $\mathrm{cm}^{-1}$ (Figs. 3 and 4) suggested that these antibiotics contained guanidino groups. Ashimycin A was positive to Sakaguchi, maltol and ElsonMorgan reactions, while ashimycin B was negative to Elson-Morgan reaction.

\section{Structures of Ashimycins A and B}

In the $400 \mathrm{MHz}{ }^{1} \mathrm{H}$ NMR spectrum of ashimycin $\mathrm{A}$ in $\mathrm{D}_{2} \mathrm{O}$ (Fig. 5), three anomeric proton signals were observed at $\delta 5.30\left(J_{1^{\prime}, 2^{\prime}}=1.4 \mathrm{~Hz}\right.$, $\left.1^{\prime}-\mathrm{H}\right), 5.74\left(J_{1^{\prime \prime}, 2^{\prime \prime}}=3.5 \mathrm{~Hz}, 1^{\prime \prime}-\mathrm{H}\right)$ and $5.36(\mathrm{~s}$, $\left.1^{\prime \prime \prime}-\mathrm{H}\right)$. The first two were ascribed to the anomeric protons of streptose and $N$-methylglucosamine, respectively. The last singlet signal at $\delta_{\mathrm{H}} 5.36$ was assigned to the anomeric proton
Fig. 2. HPLC analysis of the fermentation broth of Streptomyces griseus FT3-4.

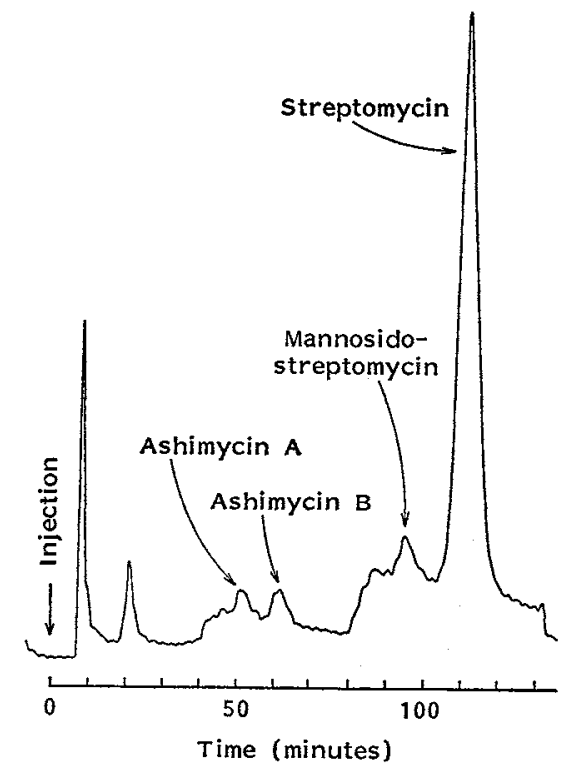

Column: CK10S $(7.0 \times 250 \mathrm{~mm})$, mobile phase; $0.2 \sim 1.0 \mathrm{M} \mathrm{Na}_{2} \mathrm{SO}_{4}, \mathrm{pH} 3.5$ (gradient), detection; maltol reaction.

Table 1. Physico-chemical properties of ashimycins A and B.

\begin{tabular}{|c|c|c|}
\hline & Ashimycin A & Ashimycin B \\
\hline Appearance & White amorphous powder & White amorphous powder \\
\hline $\mathrm{MP}\left({ }^{\circ} \mathrm{C}\right)$ & 150 & 205 \\
\hline Optical rotation $[\alpha]_{\mathrm{D}}^{23}$ & $-37.0^{\circ}\left(c 1.0, \mathrm{H}_{2} \mathrm{O}\right)$ & $-85.3^{\circ}\left(c 0.04, \mathrm{H}_{2} \mathrm{O}\right)$ \\
\hline $\mathrm{SI}-\mathrm{MS}(m / z,(\mathrm{M}+\mathrm{H}))$ & 758 & 640 \\
\hline Molecular formula & $\mathrm{C}_{27} \mathrm{H}_{47} \mathrm{~N}_{7} \mathrm{O}_{18} \cdot 1 \frac{1}{2} \mathrm{H}_{2} \mathrm{SO}_{4} \cdot 2 \mathrm{H}_{2} \mathrm{O}$ & $\mathrm{C}_{23} \mathrm{H}_{41} \mathrm{~N}_{7} \mathrm{O}_{14} \cdot \mathrm{H}_{2} \mathrm{SO}_{4} \cdot \mathrm{H}_{2} \mathrm{O}$ \\
\hline Elemental analysis & $\begin{array}{lll}\mathrm{C} & \mathrm{H} & \mathrm{N}\end{array}$ & $\mathrm{C} \quad \mathrm{H} \quad \mathrm{N}$ \\
\hline Calcd: & $34.47,5.79,10.42$ & $36.56,6.00,12.98$ \\
\hline Found: & $34.10,5.68,10.15$ & $36.39,6.04,13.31$ \\
\hline IR $\nu_{\max }^{\mathrm{KBr}} \mathrm{cm}^{-1}$ & $3400,1660,1630,1400,1100,600$ & $3340,1660,1630,1400,1100,600$ \\
\hline \multicolumn{3}{|l|}{ Color reaction } \\
\hline Positive: & Sakaguchi, maltol, Elson-Morgan & Sakaguchi, maltol \\
\hline Negative: & & Elson-Morgan \\
\hline
\end{tabular}


Fig. 3. IR spectrum (KBr) of ashimycin $A$.

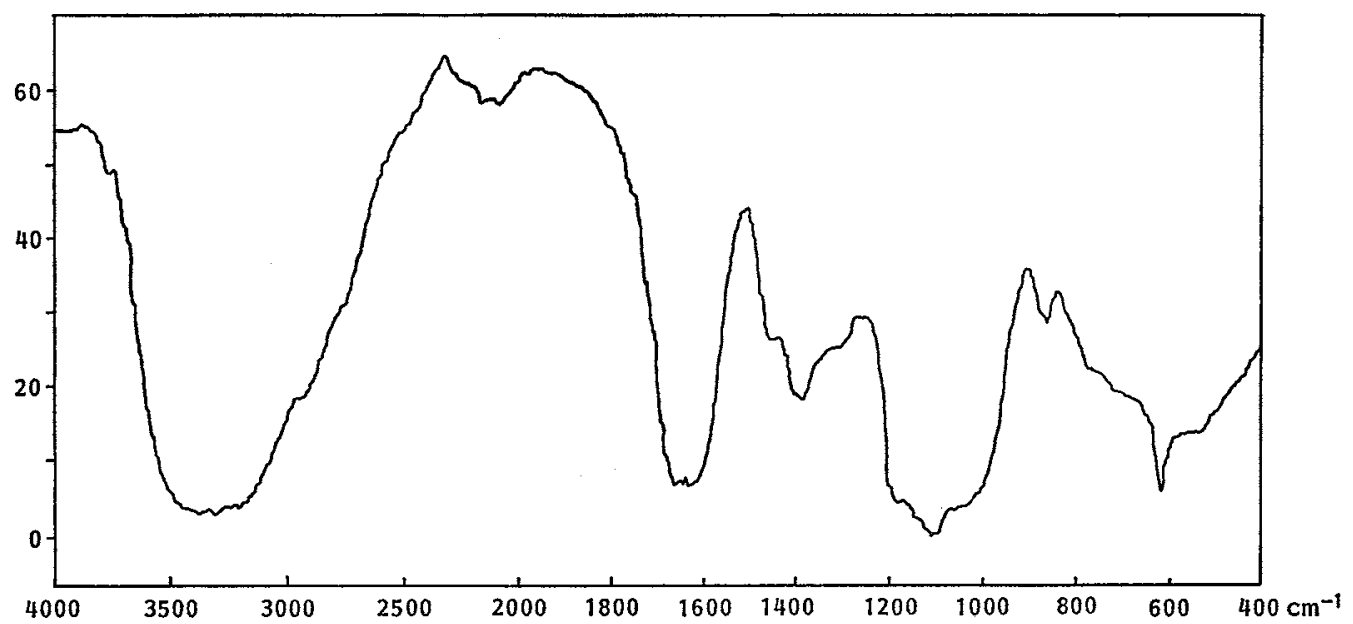

Fig. 4. IR spectrum (KBr) of ashimycin $B$.

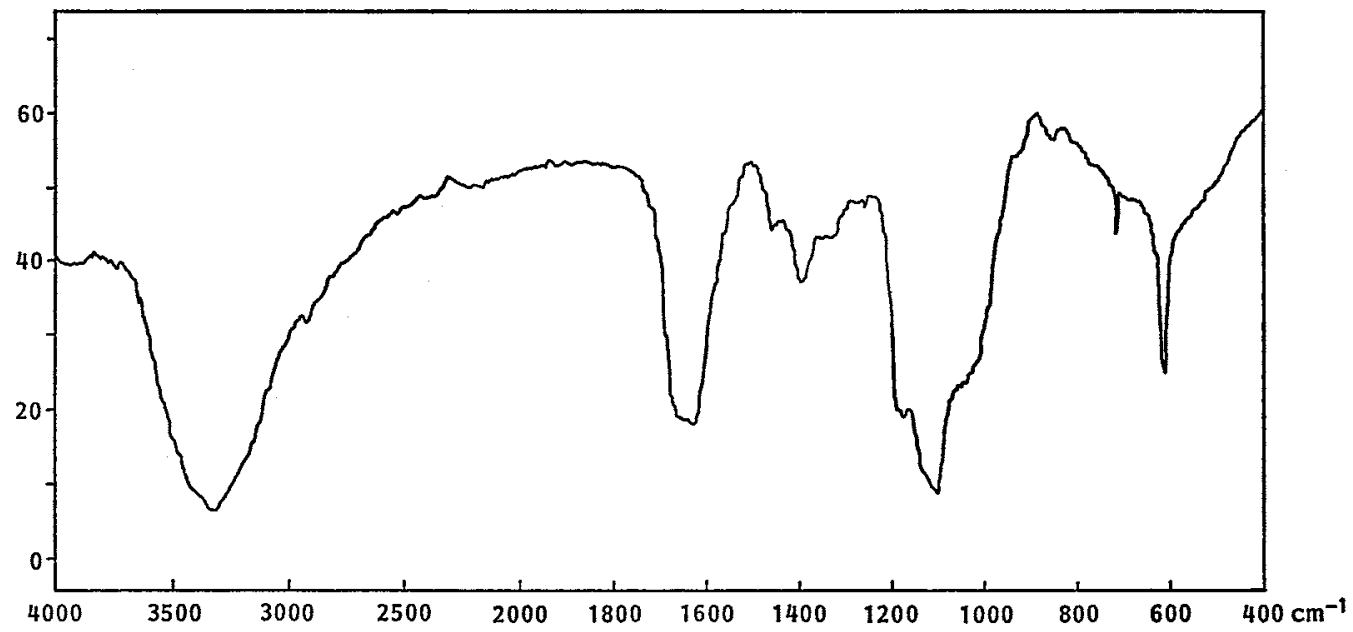

of a new sugar moiety. ${ }^{13} \mathrm{C}$ NMR spectral comparison of ashimycin A and streptomycin (Table 2) suggests that the new antibiotic is structurally very similar to streptomycin except for the presence of a new sugar ${ }^{1,2)}$. The functionalities of the carbon atoms in the new sugar are as follows; $1 \times$ anomeric carbon, $1 \times \mathrm{COOH}, 1 \times \mathrm{C}-\mathrm{O}, 2 \times \mathrm{CH}-\mathrm{O}$ and $1 \times \mathrm{CH}_{2}-\mathrm{O}$. The partial structures of the new sugar from $\mathrm{C}-3^{\prime \prime \prime}$ to $\mathrm{C}-5^{\prime \prime \prime}$ (Fig. 6) were determined by proton spin decoupling experiments. The ${ }^{13} \mathrm{C}$ chemical shifts of $\mathrm{C}-4^{\prime \prime \prime}(\delta 83.3)$ and $\mathrm{C}-5^{\prime \prime \prime}\left(\delta\right.$ 62.0) are very similar to those of $\mathrm{C}-4^{\prime}$ and $\mathrm{C}-5^{\prime}$ of $9-$ $\beta$-D-xylofuranosyl adenine $\left(\delta_{\mathrm{C}} 83.0 \text { and } 60.0 \text { respectively }\right)^{3)}$, suggesting that $\mathrm{C}-4^{\prime \prime \prime}$ must be attached to $\mathrm{C}-1^{\prime \prime \prime}$ via an ethereal oxygen. The downfield shift of $\mathrm{C}-4$ "' is reasonably explained in terms of an alkylation shift. Since $\mathrm{C}-1^{\prime \prime \prime}$ and $\mathrm{C}-3^{\prime \prime \prime}$ were not coupled to each other, they must be separated by a quaternary oxycarbon $(\delta 82.0)$ and the carboxyl group is therefore linked to $\mathrm{C}-2^{\prime \prime \prime}$. Furthermore, the presence of a carboxyl group in ashimycin $\mathrm{A}$ was revealed by positive coloration of a hydroxamic acid derivative ${ }^{4)}$. The configurations of $\mathrm{C}-1^{\prime \prime \prime}$ and $\mathrm{C}-2^{\prime \prime \prime}$ remain to be established. 
Fig. 5. $400 \mathrm{MHz}{ }^{1} \mathrm{H}$ NMR spectrum of ashimycin A.

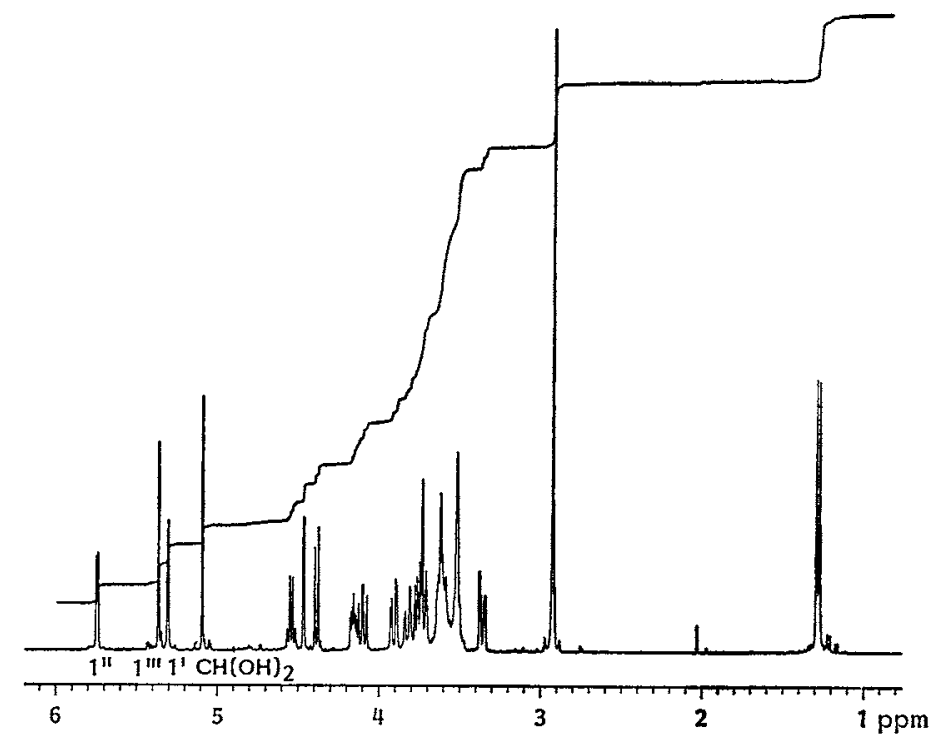

The position of the new sugar within the molecule was determined as follows. Compared with streptomycin, $\mathrm{C}-4^{\prime \prime}$ is shifted downfield by $8.5 \mathrm{ppm}$, and $\mathrm{C}-3^{\prime \prime}$ and $\mathrm{C}-5^{\prime \prime}$ are shifted upfield by 1.8 and $1.9 \mathrm{ppm}$, respectively, in ashimycin A. Thus, the C-4" position of the streptomycin moiety is glycosylated by the new sugar in ashimycin A. Accordingly, the structure of ashimycin $\mathrm{A}$ was determined as shown in Fig. 7. We propose to name the new sugar as ashimose. A sugar with the same planar structure had been prepared by oxidation of methyl $\beta$-D-glucopyranoside with oxygen in alkaline, aqueous solution ${ }^{5}$.

In the $200 \mathrm{MHz}{ }^{1} \mathrm{H}$ NMR spectrum of ashimycin $\mathrm{B}$ in $\mathrm{D}_{2} \mathrm{O}$ (Fig. 8), two anomeric proton signals were observed at $\delta 5.35\left(J_{1^{\prime}, 2^{\prime}}=1.5 \mathrm{~Hz}\right.$, $\left.1^{\prime}-\mathrm{H}\right)$ and $5.70\left(J_{1^{\prime \prime}, 2^{\prime \prime}}=3.4 \mathrm{~Hz}, 1^{\prime \prime}-\mathrm{H}\right)$. The ${ }^{13} \mathrm{C}$ NMR spectrum (Table 2) suggests that ashimycin B is structurally very similar to streptomycin except for the presence of two new signals due to carbonyl $\left(\delta_{\mathrm{C}} 171.5\right)$ and methylene $\left(\delta_{\mathrm{C}} 58.9\right)$ carbons, assignable to a glycolic acid moiety $\left(\delta_{\mathrm{C}} \mathrm{C}-1,177.0 \text { and } \mathrm{C}-2,60.5\right)^{6)}$. The downfield shifts of $\mathrm{NCH}_{3}$ by $8.2 \mathrm{ppm}$ and of $\mathrm{C}-2^{\prime \prime}\left(\delta_{\mathrm{c}} 66.4\right)$
Table 2. ${ }^{13} \mathrm{C}$ NMR shifts of ashimycins $\mathrm{A}$ and $\mathrm{B}^{\mathrm{a}}$.

\begin{tabular}{|c|c|c|c|}
\hline Carbon & $\underset{\text { A }}{\text { Ashimycin }}$ & $\underset{B}{\operatorname{Ashimycin}}$ & $\begin{array}{l}\text { Strepto- } \\
\text { mycin }\end{array}$ \\
\hline 1 & 59.6 & 59.7 & 59.7 \\
\hline 2 & 72.1 & 71.7 & 71.5 \\
\hline 3 & 59.3 & 59.3 & 59.0 \\
\hline 4 & 76.6 & 78.7 & 78.9 \\
\hline 5 & 74.3 & 74.0 & 74.2 \\
\hline 6 & 72.3 & 72.4 & 72.4 \\
\hline $\mathrm{C}=\mathrm{NH}(1)$ & 159.1 & 159.1 & 159.1 \\
\hline $\mathrm{C}=\mathrm{NH}(3)$ & 158.3 & 158.5 & 158.6 \\
\hline $1^{\prime}$ & 107.3 & 106.4 & 106.7 \\
\hline $2^{\prime}$ & 81.6 & 84.1 & 85.3 \\
\hline $3^{\prime}$ & 83.4 & 83.2 & 83.1 \\
\hline $4^{\prime}$ & 78.8 & 78.0 & 78.3 \\
\hline $5^{\prime}$ & 12.3 & 13.7 & 13.4 \\
\hline $\mathrm{CHO}\left(3^{\prime}\right)$ & 89.9 & 90.5 & 90.5 \\
\hline $1^{\prime \prime}$ & 92.6 & 95.9 & 95.2 \\
\hline $2^{\prime \prime}$ & 62.0 & 66.4 & 62.3 \\
\hline $3^{\prime \prime}$ & 68.6 & 68.4 & 70.4 \\
\hline $4^{\prime \prime}$ & 78.6 & 71.0 & 70.1 \\
\hline $5^{\prime \prime}$ & 71.8 & 73.5 & 73.7 \\
\hline $6^{\prime \prime}$ & 60.2 & 61.3 & 61.2 \\
\hline $\mathrm{NCH}_{3}\left(2^{\prime \prime}\right)$ & 32.7 & 41.3 & 33.1 \\
\hline $\mathrm{C}=\mathrm{O}$ & & 171.5 & \\
\hline $\mathrm{CH}_{2} \mathrm{OH}$ & & 58.9 & \\
\hline $1^{\prime \prime \prime}$ & 106.7 & & \\
\hline $2^{\prime \prime \prime}$ & 82.0 & & \\
\hline $3^{\prime \prime \prime}$ & 74.3 & & \\
\hline $4^{\prime \prime \prime}$ & 83.3 & & \\
\hline $5^{\prime \prime \prime}$ & 62.0 & & \\
\hline $\mathrm{COOH}$ & 177.2 & & \\
\hline
\end{tabular}

From internal dioxane in ppm. pD 5.5.

a For the assignments of streptomycin and related substances, see refs 1 and 2 . 
Fig. 6. Partial structures of ashimycin A.
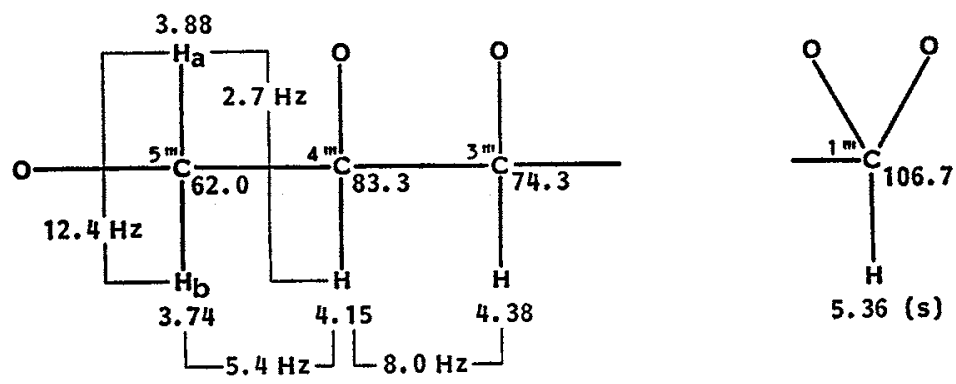

Fig. 7. Structures of ashimycins A and B.

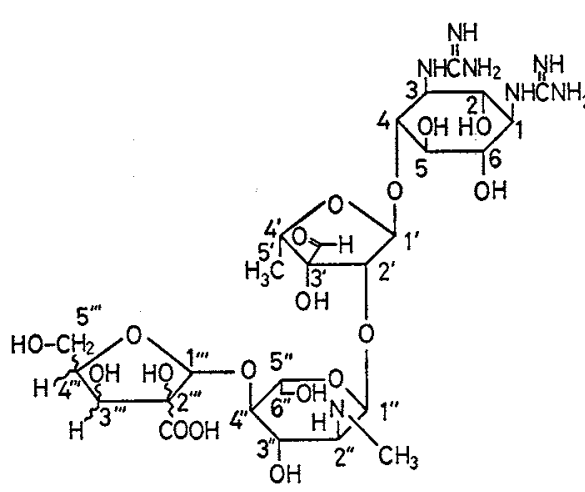

Ashimycin A

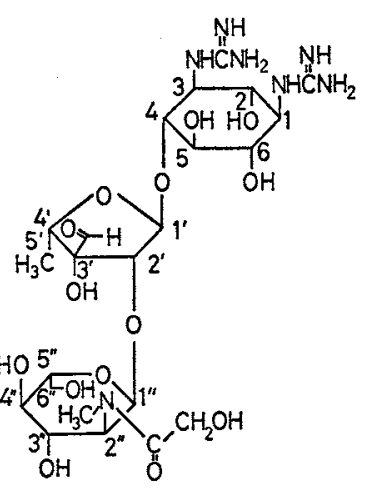

Ashimycin B

Fig. 8. $200 \mathrm{MHz}{ }^{1} \mathrm{H}$ NMR spectrum of ashimycin B.

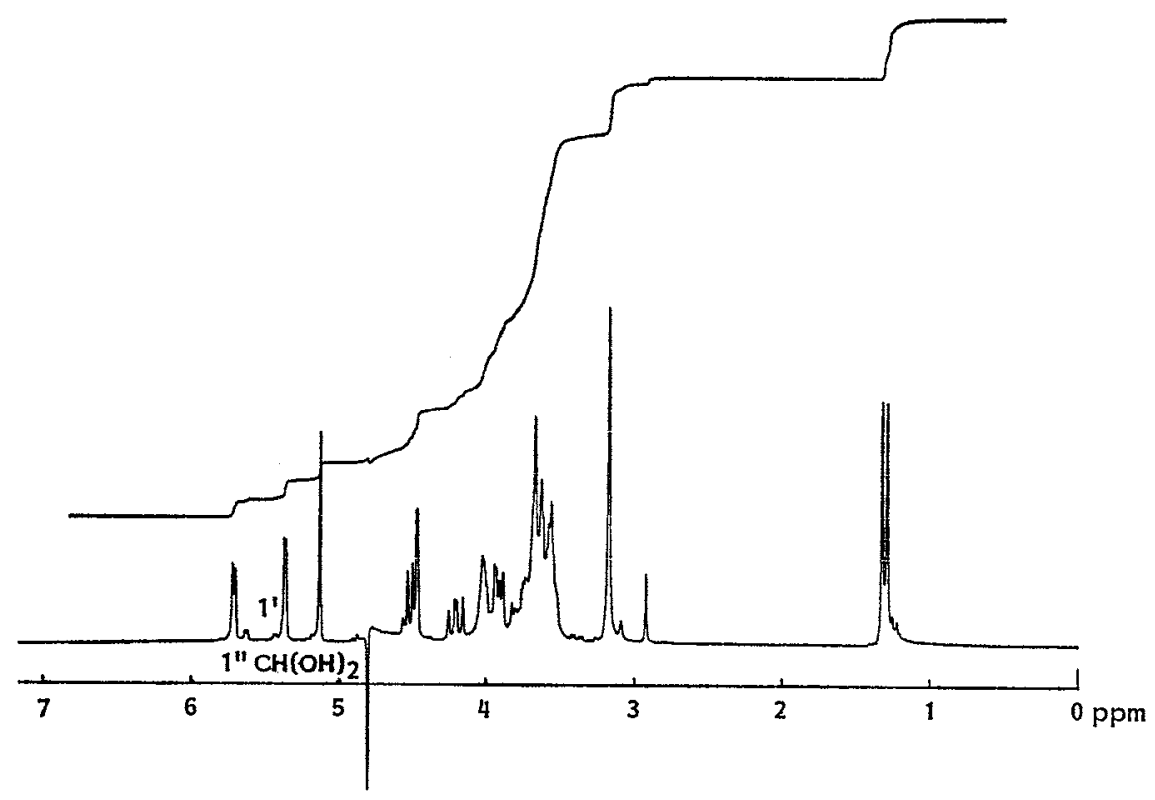

by $4.1 \mathrm{ppm}$ in the ${ }^{13} \mathrm{C}$ NMR data of ashimycin B suggest that the $N$-methyl group is acylated 1 glycolic acid in ashimycin B. In agreement with this conclusion, long range selective proton decour ing (LSPD) of the $N$-methyl proton collapsed the carbonyl carbon signal $\left(\delta_{0} 171.5\right)$ to a broc 
Fig. 9. $200 \mathrm{MHz}{ }^{1} \mathrm{H}$ NMR spectrum of methyl $N$-glycolyl- $N$-methylglucosaminide peracetate.

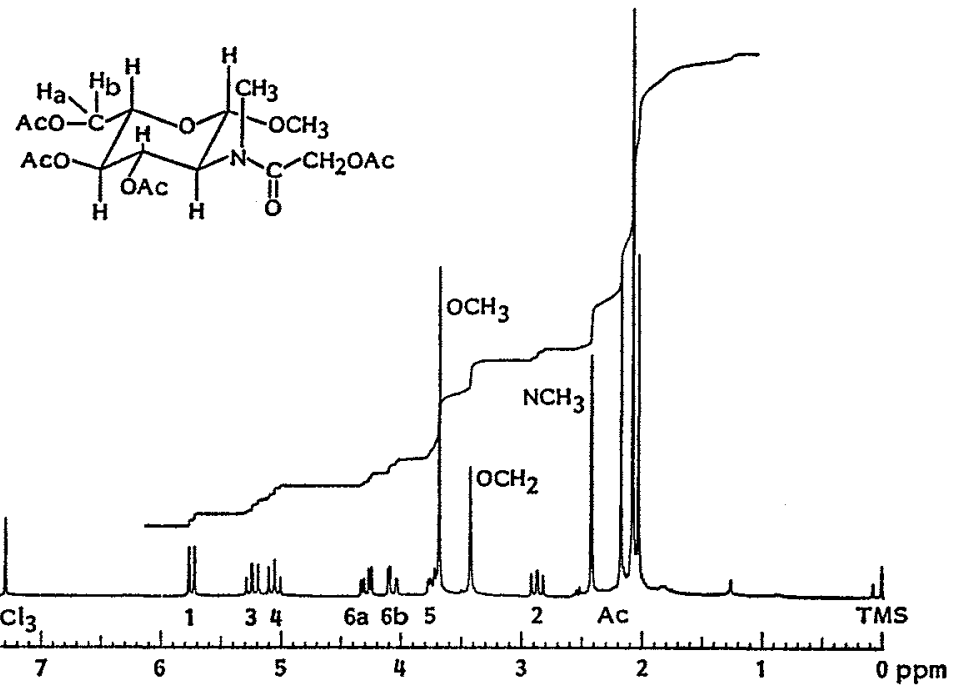

Table 3. Antibacterial activities of ashimycins A and B.

\begin{tabular}{lccc}
\hline \multicolumn{1}{c}{ Test organisms } & Ashimycin A & Ashimycin B & Streptomycin \\
\hline Staphylococcus aureus Smith I & 50 & 12.5 & 1.56 \\
S. aureus FDA 209P & 25 & 25 & 1.56 \\
S. aureus Apo-1 & 50 & 50 & 3.13 \\
S. epidermidis 109 & 50 & 100 & 100 \\
Micrococcus flavus FDA 16 & 100 & 25 & 1.56 \\
Bacillus anthracis & 50 & 12.5 & 0.78 \\
B. subtilis PCI 219 & 25 & 6.25 & 0.39 \\
Corynebacterium bovis 1810 & 100 & 25 & 1.56 \\
Escherichia coli K-12 R-5 & 50 & 100 & 100 \\
E. coli NIHJ JC-2 & 50 & 25 & 3.13 \\
Klebsiella pneumoniae & 200 & 25 & 1.56 \\
Proteus vulgaris OX19 & 50 & 12.5 & 1.56 \\
P. rettgeri GN311 & 25 & 12.5 & 0.78 \\
\hline
\end{tabular}

MIC $(\mu \mathrm{g} / \mathrm{ml})$ in Mueller-Hinton agar.

doublet signal $(J=4.9 \mathrm{~Hz})$. Furthermore, the $N$-methyl proton $\left(\delta_{\mathrm{H}} 3.16\right)$ of ashimycin B is shifted downfield by $0.26 \mathrm{ppm}$ as compared with the corresponding proton of streptomycin $\left(\delta_{\mathrm{H}} 2.90\right)$.

In order to confirm the structure of ashimycin $\mathrm{B}$, it was subjected to acid catalyzed hydrolysis. Ashimycin $\mathrm{B}$ was dissolved in $1 \mathrm{~N} \mathrm{H}_{2} \mathrm{SO}_{4}$ and allowed to stand at room temperature for 18 hours. After removal of precipitated streptidine sulfate by filtration, the filtrate was treated with concentrated $\mathrm{HCl}$ for 2 hours at $100^{\circ} \mathrm{C}$. The residue was passed through a column of Dowex $50\left(\mathrm{H}^{+}\right)$and then an $N-$ methylglucosamine derivative was eluted with $4 \mathrm{~N} \mathrm{NH}_{4} \mathrm{OH}$. Treatment of the dried hydrolysate with $\mathrm{HCl}$ - methanol solution, followed by acetylation with acetic anhydride in the presence of anhydrous sodium acetate gave a crude powder of methyl $N$-glycolyl- $N$-methylglucosaminide peracetate. This material was purified by silica gel chromatography eluting with $\mathrm{CHCl}_{3}-\mathrm{CH}_{3} \mathrm{OH}(100: 1)$. Physicochemical properties of the peracetate were as follows: $[\alpha]_{\mathrm{D}}^{23}-22.8^{\circ}\left(c 0.07, \mathrm{CHCl}_{3}\right)$; SI-MS $m / z 434$ $(\mathrm{M}+\mathrm{H})^{+}$; the $200 \mathrm{MHz}^{1} \mathrm{H}$ NMR spectrum in $\mathrm{CDCl}_{3}$ is shown in Fig. 9. 
